\title{
Cheating in the wake of COVID-19: How dangerous is ad-hoc online testing for academic integrity?
}

\author{
Stefan Janke ${ }^{\mathrm{a}, *}$, Selma C. Rudert ${ }^{\mathrm{b}}, \ddot{\text { Änne Petersen }}{ }^{\mathrm{a}}$, Tanja M. Fritz ${ }^{\mathrm{c}}$, Martin Daumiller ${ }^{\mathrm{c}}$ \\ ${ }^{\text {a }}$ University of Mannheim, School of Social Sciences, Germany \\ ${ }^{\mathrm{b}}$ University of Koblenz and Landau, Germany

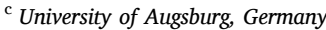

\section{A R T I C L E I N F O}

\section{Keywords:}

Academic dishonesty

Cheating

Examination

Online testing

\begin{abstract}
A B S T R A C T
Worldwide, higher education institutions made quick and often unprepared shifts from on-site to online examination in 2020 due to the COVID-19 health crisis. This sparked an ongoing debate on whether this development made it easier for students to cheat. We investigated whether students did indeed cheat more often in online than in on-site exams and whether the use of online exams was also associated with higher rates of other behaviors deemed as academic dishonesty. To answer our research questions, we questioned 1608 German students from a wide variety of higher education institutions about their behavior during the summer semester of 2020 . The participating students reported that they cheated more frequently in online than in on-site exams. Effects on other measures of academic dishonesty were negligible. These results speak for the notion that the swift application of ad-hoc online testing during 2020 has led to negative consequences for academic integrity.
\end{abstract}

The COVID-19 pandemic forced many higher education institutions across the globe to apply new ways of teaching and testing to mitigate health risks for instructors and students. Especially the increased reliance on online exams has ignited debates on whether this method of performance assessment comes with higher risks for academic integrity than on-site exams, as students supposedly have more opportunities to cheat $[11,22,42]$. While prior research on academic dishonesty is inconclusive regarding the question of whether online testing fosters dishonest behavior [26], the extensive and sudden shift from on-site to online testing in the higher education sector in the wake of the pandemic represents an unparalleled event. More than the previous small steps towards digitalization, this large-scale change in performance assessment provided a challenge for maintaining academic integrity. Higher education practitioners often had little time to prepare for the transition [4]. As a result, educators relied on a range of ad-hoc solutions to testing, many of which were characterized by low accountability and less than optimal procedures to monitor students' behavior during the assessment situation [15]. From the students' perspective, the anticipation of less accountability for cheating in combination with difficulties to prepare for the online exams (e.g., due to new family and community obligations emerging during COVID-19, unfamiliarity with new exam formats, or a lack of necessary self-regulated learning skills, [42]), might have increased the appeal to cheat in online exams. In the present work, we investigate whether students did indeed cheat more during the COVID-19 pandemic when examined through online exams compared to on-site exams, and whether a shift in the mode of examination was also associated with elevated rates of further dishonest behaviors (e.g., more plagiarism, lying or bribing of university instructors for better grades).

\section{Academic dishonesty in virtual environments}

Broadly defined, academic dishonesty refers to a set of behaviors that can be understood as an intentional breaking of academic rules for personal gain (e.g., plagiarism, lying, and falsifications). Such a definition is best reflected in multifaceted models of academic dishonesty (see, for instance, [7]). However, academic dishonesty can also be defined more narrowly in terms of singular clear-cut behaviors such as cheating in exams (e.g., [21]). The terms academic dishonesty and cheating are as a result sometimes used interchangeably within the literature. Here, we use the term academic dishonesty or dishonest behavior when referring to the broader multifaceted construct. In contrast, we use the term cheating when referring to the more narrowly defined behavior of using unallowed material or unallowed assistance during exams.

Both academic dishonesty in general and cheating during exams in

E-mail address: stefan.janke@uni-mannheim.de (S. Janke).

* Corresponding author. 
particular are highly prevalent in higher education institutions. Prior research has repeatedly shown that the majority of students admit to having engaged in academic dishonesty during their studies [9,38,52]. This finding has inspired a multitude of research frameworks aiming to explain which personal and environmental factors can elevate or reduce cheating rates. Exemplary theories on such factors include social norms theory, explaining cheating as a result of injunctive and descriptive norms $[5,40]$, deterrence theory that focuses on how expectations about punishment impact cheating [14], and cognitive theories focusing on the impact of neutralization techniques and feelings of entitlement [50].

The present contribution relies on more general theoretical approaches that aim to integrate several singular factors into more general frameworks and provide a comprehensive picture of impact factors. Particularly, we build on models that explain human behavior as a function of outcome expectations, outcome value, and costs (e.g., [56]). In the terms of such models, academic dishonesty may be understood as a function of students' evaluation of the potential outcome of dishonest behavior, their perceived ability to succeed without dishonesty as well as on (external and internal) costs bound to the expected likelihood of potential sanctions [43].

Under normal conditions (i.e., outside of the pandemic), the implementation of online exams will likely neither impact students' expectations to succeed in an exam by regular means nor influence the outcome value of a good grade in the exam. However, online exams may lower the expected costs of cheating, given that both faculty members $[42,47]$ as well as students $[16,29]$ share the belief that it is easier to get away with cheating in online exams. This could facilitate higher cheating rates in online exams compared to on-site exams even under normal conditions, that is, without an acceleration of digitalization due to a worldwide health crisis.

Empirically, the number of studies comparing the frequency of cheating between on-site and online exams is limited to less than a dozen studies [26]. The results of these studies are inconclusive, with some demonstrating higher cheating rates [28,30,34] and others showing steady $[33,54]$ or even lower rates [23,51]. Holden and colleagues [26] argue that these inconsistencies could partly be due to different operationalizations of cheating. To this end, previous studies differed in whether they explicitly focused on cheating in online exams or compared a multitude of aspects of academic dishonesty depending on the mode of teaching (online vs. on-site).

Studies that explicitly focused on the impact of the examination mode on cheating during the exam showed that online exams were associated with increased cheating compared to on-site exams [28,30]. This could be due to instructors implementing examination environments that do not sufficiently allow to shape and monitor the physical testing environment. As a result, students may feel less accountable and less likely to be caught cheating during online exams. In contrast, studies that focused on the question whether the mode of teaching impacted wider arrays of dishonest behavior typically yielded smaller effects [23,54], possibly because the teaching process itself may not impact students' perception of accountability. In sum, we assume that the mode of examination impacts cheating rates to a stronger degree than the shift to online teaching.

Practitioners in higher education have proposed solutions to address reduced accountability for cheating in online exams. One such solution is the use of proctoring, that is, ensuring academic integrity with methods such as live observation via webcam or delayed checks for fraudulent behavior through recordings. In fact, results from empirical research indicate that proctoring online exams reduced the inflated performance rates that can be observed in online exams without proctoring $[2,19,46]$, while also enhancing the perceived accountability for academic dishonesty [27]. A further solution to reduce cheating is to make consequences for cheating more salient, for instance by letting students read and copy warning statements about potential sanctions [53]. Finally, researchers have promoted changes in the overall design of online exams by advocating open-ended questions over multiple-choice [6], open-book exams [57], or even collaborative exams [48]. These changes make cheating either less feasible (open-ended questions) or even encourage behaviors that are typically considered as cheating (collaboration and use of textbooks/internet resources during the exam) to facilitate deeper processing of the learning material.

However, several factors can deter instructors from using strategies to mitigate cheating, starting with a lack of knowledge about these procedures, a lack of motivation to implement them, and also technical issues such as a lack of access to proctoring software. This was likely a problem during the onset of the COVID-19 pandemic, when higher education instructors with little experience and restricted time had to familiarize themselves with online testing [44], while higher education institutions often still lacked both the technical expertise as well as the legal foundation for certain methods such as proctoring [13].

\subsection{COVID-19 and online exams: ad-hoc solutions as a response to rapid changes}

The COVID-19 pandemic led to a severe disruption of teaching throughout higher education institutions around the world [37]. University instructors had to find swift responses and often shifted from on-site to online teaching in a matter of days [17]. This meant that higher education practitioners were fully occupied by setting up virtual learning environments, exploring tools they had never used before, and searching for ways to engage with their students, which was often perceived as a straining experience [4]. Regarding testing, instructors had to rely on a wide range of local ad-hoc solutions often bound to official guidelines that higher education institutions and government agencies had developed under strong time pressure. While some early adopters that already had experience with online testing prior to COVID-19 may have coped better with this transition, it stands to reason that this applied only to a small minority of institutions and instructors [15].

Differences in approaches to online testing might be further complicated by political developments and structures, as can be exemplified by the situation in the higher education sector of Germany in 2020. Like most of Western Europe, Germany was hit by a spike of COVID-19 infections during spring 2020. The first response to slow down the spread of the infections (e.g., regulations regarding social contacts, lockdown of educational institutions) was coordinated throughout the country. However, Germany is a decentralized country with federal states and municipalities having relatively high autonomy. Thus, as the first wave of the pandemic decreased, some of those measures were adapted or changed on a state or even municipal level during summer 2020. In the higher education sector, this led to vastly different approaches to teaching and examination between federal states ("Länder") and even between institutions [17]. Some institutions chose to administer on-site exams (for instance to mitigate risks for academic integrity). Other institutions focused more strongly on minimizing health risks and either used a mixture of online and on-site exams or completely shifted examination procedures to online testing.

The impact of the rapid digital transformations in the higher education sector on academic integrity is an emerging topic. First studies already shed some light on this issue. For instance, elevated concerns about cheating among instructors [42] as well as among students [20], indicative data such as a spike in internet searches for key terms during testing periods [11], or an increase in performance compared to prior cohorts (also [11]) can be interpreted as first evidence for a potential threat to academic integrity. To supplement this research and advance our understanding on what actually happened after the swift shift in examination procedures in summer 2020, we investigate students' academic dishonesty through self-report measures. A benefit of students' reports is that they directly capture students' experiences so that no further inferences are needed to concur that cheating or other kinds of dishonest behaviors happened.

\subsection{Hypotheses on the impact of rapid digitalization of examinations on academic integrity}

We distinguish between three potential hypotheses regarding the impact of sudden shifts in examination procedures on academic 
dishonesty: (1) the unproblematic-digitalization hypothesis, (2) the selective-behavior-change hypothesis and (3) the strong-threat-tointegrity hypothesis. The unproblematic-digitalization hypothesis aligns with research suggesting that online testing is associated with similar or lower cheating rates than on-site testing $[23,33,51,54]$ as well as the notion that both on-site and online assessments can be tailored to combat cheating [2,27]. This hypothesis builds on the assumption that instructors' abilities and efforts to uphold academic integrity do not systematically differ between modes of examination, and consequently assumes that the shift to online exams does not impair academic integrity.

However, in contrast to a careful development of online testing procedures, it seems more likely that sudden shifts to online testing may have led to a rather chaotic implementation of less secure ad-hoc solutions, which in turn reduced instructors' ability to detect cheating during examination. In terms of overarching theories of cheating, we would assume that teachers' lowered capability and/or motivation to detect cheating in online exams taken together with students' assumptions that cheating is easier in online exams [16] may have reduced anticipated costs of cheating. This in turn can be expected to lead to higher rates of cheating in online compared to on-site exams in times of higher uncertainty during the pandemic. One may assume two different scenarios for this rise in dishonesty: The first scenario is that a shift to less secure online testing procedures yields higher rates of cheating during tests, but not in other academic situations. This selective-behavior-change hypothesis aligns well with the notion of Holden and colleagues [26] that most empirical studies found online exams to be associated with an increase in using specific means of cheating during the exam itself, but not with an increase in more general measures of academic dishonesty.

A second scenario is that the chaotic shift of paradigms during the pandemic affected instructors and students even more severely: On the one hand, instructors might have been overwhelmed and absent, and not been willing or able to invest more time into implementing optimal testing procedures. On the other hand, students might have experienced increased fear of failure due to unfamiliar modes of teaching, testing, and the higher importance of self-regulated learning [24]. If this were true, students would have both experienced a lower accountability for any kind of dishonest behavior, paired with a low expectation to succeed without relying on such behavior. This might have led to a strong threat to academic integrity that manifested itself in an increase of further dishonest behavior beyond the scope of cheating in exams (e.g., enhanced rates of plagiarism, fabricating in essays, or bribing of university instructors for better grades).

Within the present contribution, we aim to shed light on the question of whether the rapid change from onsite to online testing during the academic summer semester 2020 (beginning of April - end of September) in Germany was (a) unproblematic regarding academic dishonesty in general and cheating in particular, or whether (b) the introduced online exams were characterized by elevated cheating rates compared to on-site exams, or (c) whether a change in mode of examination was associated not only with more cheating but also higher rates of academic dishonesty overall. Additionally, we investigated whether experience of an institution with online exams moderated the association between mode of examination and academic dishonesty.

\section{Material and methods}

We conducted a nation-wide online assessment throughout Germany in November/December 2020 (two months after the end of the summer semester) in which we contacted students through official mailing lists of all higher education institutions willing to participate in the study. As participants were promised full anonymity due to the sensitivity of the subject matter, we did not assess any information about participants' specific institution and thus cannot state how many and which different institutions distributed our survey. However, we asked the participants in which federal state they were studying and about the type of higher education institution they were enrolled in (see participants section for more information). As all sixteen federal states and several types of higher education institutions were represented, we infer that our sample is characterized by a strong diversity of educational institutions.

\subsection{Participants}

In total, 3005 students started filling out the questionnaire. For our analyses, we decided to exclude all students who (a) stopped answering the questionnaire before filling out any items on academic dishonesty (presented at the very end of the survey), (b) were not enrolled at university in the prior semester (summer semester 2020) as they had no chance to commit dishonest actions in the assessed period and (c) students who failed to correctly answer an attention check that was included in the questionnaire ("please use the option furthest to the right side of the screen to answer this item.") as this indicated that the participants were not paying attention when answering the items. Moreover, we excluded students who had not taken any written exams in the summer semester because the measures assessing cheating during online examination pertained to written exams. Most of the students (80.60\%) indicated that their performance had been assessed through some sort of written exam during the summer semester 2020.

Overall, the net sample included 1608 students (Age: $M=23.08$ years, $S D=3.86$ years; Gender: $68.7 \%$ female, $0.8 \%$ diverse; Study duration: $M$ $=4.41$ semesters, $S D=2.16$ semesters; Bachelor level: 78.5\%, Master level: $12.4 \%$, other study programs including diploma or "Staatsexamen" programs: $8.8 \%$ ). Most students were enrolled at research-focused universities (41.2\%), but also at universities of applied sciences ("Fachhochschulen"; 24.4\%), cooperative state universities ("Duale Hochschulen"; 29.0\%), universities of education ("Pädagogische Hochschulen"; 2.4\%), distance learning universities ("Fernuniversitäten"; $0.5 \%$ ), and other higher education institutions (2.4\%). Most of the participating students had enrolled in business and economic programs (31.6\%) followed by education (10.8\%), mechanical engineering $(8.6 \%)$, social management $(4.9 \%)$, computer science $(4.9 \%)$, medicine $(4.8 \%)$, German studies (4.7\%), mathematics (3.7\%), and a wide array of further programs (33 categories $<3.0 \%$ of the sample). The sample was, thus, characterized by a broad variety of disciplines and institutions.

The majority of the investigated students $(82.5 \%)$ indicated that they were exclusively taught through online courses during the summer semester 2020. Additionally, $16.6 \%$ of the participants indicated that their faculty had employed a mixture of online and on-site teaching (likely due to semesters disrupted by lockdown measures), whereas only $0.9 \%$ indicated that they were taught exclusively on-site.

\subsection{Measures}

\subsubsection{Mode of examination}

Participants indicated whether their performance had been assessed via exams during the summer semester 2020. If the students indicated that this was the case, we asked them about the total number of on-site and/or online exams that they had participated in during the semester. We used this data to code the mode of examination $(1=$ on-site only; $2=$ online only; 3 = mixed mode of examination).

\subsubsection{Academic dishonesty}

All students indicated how frequently they had engaged in deviations from academic integrity during the summer semester 2020. In total, we assessed 19 different behaviors with a frequency scale ranging from 1 (never) to 7 (very frequently). The benefit of using a set of pre-defined behaviors rather than simply asking students about whether they perceived their behavior as dishonest or unethical is that students' assessment of whether certain behaviors are acceptable or not is characterized by low objectivity and validity [12]. The behaviors assessed within our questionnaire were largely adopted from pre-existing measures of academic dishonesty [7,39] and included behaviors such as plagiarism, fabrication, tempering with learning material, lying, and bribing (see Table 2 for a full depiction). Two of the items specifically aimed at behavior during online courses with live 
communication (engaging in non-course related activities while being logged in; letting others log into a course as proxies for one's own participation) and were only administered to students who had taken online courses during the summer semester ( $n=1593$ students). Besides these items, we also measured with three items whether students had assisted other students in cheating. We did not include these items in our analyses because the respective behaviors likely constitute a different kind of dishonest behavior that is focused less on personal gain. For all but the descriptive analyses, we aggregated all 19 items to a mean score for academic dishonesty $(\alpha=0.79)$.

\subsubsection{Cheating in exams}

Students who had written exams as performance assessments answered additional questions regarding cheating in exams depending on whether they were examined on-site ( 5 additional items; $n=1223$ students) or online ( 3 additional items; $n=734$ students). These items were once again based on existing measures [1,39]. If students' performance was assessed using both modes of examination, they received all eight additional items. The items were measured with the same seven-point-scale that had been used to assess the above-mentioned general aspects of academic dishonesty. Two items were content-identical between the two modes of examination and as such suitable for comparisons. These items were "During on-site/online exams, I used additional materials or the internet to solve exam questions without permission to do so." (unallowed assistance) and "During on-site/online exams, I exchanged ideas about possible answers to exam questions with others." (direct exchange). We aggregated the two items to mean scores indicating cheating during examination for further comparisons (on-site reliability: $\rho=0.66$, online reliability: $\rho=0.76$ ). The remaining four items that were unique for either testing situation were not aggregated to any score, but we still analyzed the frequency of those behaviors to assess their relative importance (see Table 2).

\subsubsection{Institutional experience with online exams}

Participants indicated whether their university had experience with online exams with one item ("Did your university use online exams before the COVID-19 pandemic?"). The students could use three options to answer the question ( $1=$ not at all; $2=$ partly; $3=$ exclusively). However, the number of students indicating that their institutions had exclusively used online exams was very low ( $n=7$ participants). Thus, we decided to merge category 2 and 3 to generate a new dichotomous measure $(0=$ no experience; $1=$ some experience).

\subsection{Analyses}

First, we calculated descriptive statistics for single behavioral variables to shed light on the frequency of the different aspects of academic dishonesty during the pandemic. In general, the items were strongly skewed with an average of $79.8 \%$ of the respondents using the first scale point (never), $6.8 \%$ the second scale point and $3.2 \%$ the third scale point per item when indicating the frequency of their behavior. This means that thefirst three of seven scale points accounted for roughly $90 \%$ of the answer pattern. While we still used the mean scores based on the frequency scale for subsequent analyses (labeled as frequency measure in the following section), we also investigated the robustness of our findings by dichotomizing the respective items post-hoc $(0=$ never, $1=$ atleastonce $)$ and then adding them into a sum score (labeled as amount measure in the following section as it indicates the total amount of different behaviors shown by the participants).

Second, we investigated whether online testing was associated with higher rates of academic dishonesty in general (full range of 19 behaviors answered by all participants) compared to on-site testing. To investigate this question, we conducted an ANOVA in which we analyzed main effects of the mode of examination on academic dishonesty.

Third, we investigated whether the mode of examination was associated with different frequencies of cheating in exams (specific behavior; 2-item-measure). As participants' tendency to cheat during exams was either measured only once (mode of examination = exclusively on-site or exclusively online) or twice (mode of examination $=$ mixture of both variants), we relied on linear mixed models using the lme4 Version 1.1.21 [8] and the lmer test package Version 3.1.1 [32] in R to estimate an overall effect of the mode of examination. We included cheating in exams as the dependent variable, mode of examination as a fixed effect, and added a random intercept for participants to the model. In an additional analysis, we included institutional experience with online exams to investigate whether the effect of mode of examination was moderated by this variable. Furthermore, we ran a repeated measure ANCOVA to investigate whether we could find any effects of the mode of examination within students that had been examined with both testing procedures, indicating a shift in behavior between testing situations. In this analysis, we additionally controlled for the ratio of online to on-site exams to control for the possibility that the dominance of one test form led to elevated rates of cheating. Note that this control for test ratio was not possible in the previously conducted mixed model analysis as the number of online exams would have been confounded with the respective mode of examination

\section{Results}

\subsection{Descriptives}

In absolute numbers, 874 of the participants reported that they took only on-site exams, while 385 of the participants reported that they took only online exams during the summer semester 2020. An additional number of 349 participants reported that they took both online and onsite exams. This shows the wide variety of solutions that had been implemented by higher education institutions during the first months of the pandemic. We provide further descriptive statistics for the three groups (characterized by the respective examination mode) in Table 1. The number of exams differed significantly based on the mode of examination. Overall, students in the online-only group took fewer exams than students who were only tested on-site, $t(811.13)=8.05, p<.001$, $d=0.47\left(M_{\text {on-site }}=4.02\right.$ tests, $S D=2.36 ; M_{\text {online }}=2.93$ tests, $\left.S D=2.13\right)$. Furthermore, students who took both types of exams also took more onsite than online exams, $F(1348)=26.54, p<.001, \eta=0.07\left(M_{\text {on-site }}=\right.$ 2.75 tests, $S D=1.98 ; M_{\text {online }}=2.02$ tests, $S D=1.35$ ).

Overall, $90.0 \%$ of the students indicated that their institution had not used online exams prior to the pandemic at all and 9.7\% indicated that their institution had at least partly or in rare cases exclusively used online exams. Interestingly, whether an institution had used online exams in the past was not predictive for whether participants took online exams during summer $2020, \chi^{2}(2)=4.05, p=.132$. More specifically,

Table 1

Descriptive statistics for the different modes of examination.

\begin{tabular}{|c|c|c|c|}
\hline & $\begin{array}{l}\text { On-site } \\
\text { exams }\end{array}$ & $\begin{array}{l}\text { Online } \\
\text { exams }\end{array}$ & $\begin{array}{l}\text { Mixed } \\
\text { testing }\end{array}$ \\
\hline \multicolumn{4}{|l|}{ General Descriptive Statistics } \\
\hline Sample Size & $n=874$ & $n=385$ & $n=349$ \\
\hline$\%$ female & $65.3 \%$ & $78.0 \%$ & $67.3 \%$ \\
\hline Age & $\begin{array}{l}M=22.90 \\
S D=3.32\end{array}$ & $\begin{array}{l}M=23.51 \\
S D=4.54\end{array}$ & $\begin{array}{l}M=23.07 \\
S D=4.26\end{array}$ \\
\hline Number of semesters & $\begin{array}{l}M=4.52 \\
S D=2.31\end{array}$ & $\begin{array}{l}M=4.08 \\
S D=1.78\end{array}$ & $\begin{array}{l}M=4.50 \\
S D=2.10\end{array}$ \\
\hline Number of on-site exams & $\begin{array}{l}M=4.02 \\
S D=2.36\end{array}$ & - & $\begin{array}{l}M=2.75 \\
S D=1.98\end{array}$ \\
\hline Number of online exams & - & $\begin{array}{l}M=2.93 \\
S D=2.13\end{array}$ & $\begin{array}{l}M=2.02 \\
S D=1.35\end{array}$ \\
\hline \multicolumn{4}{|l|}{ Academic Dishonesty } \\
\hline Frequency of academic dishonesty & $\begin{array}{l}M=1.43 \\
S D=0.42\end{array}$ & $\begin{array}{l}M=1.51 \\
S D=0.49\end{array}$ & $\begin{array}{l}M=1.47 \\
S D=0.49\end{array}$ \\
\hline $\begin{array}{l}\text { Frequency of cheating in on-site } \\
\text { exams }\end{array}$ & $\begin{array}{l}M=1.33 \\
S D=0.81\end{array}$ & - & $\begin{array}{l}M=1.65 \\
S D=1.07\end{array}$ \\
\hline $\begin{array}{l}\text { Frequency of cheating in online } \\
\text { exams }\end{array}$ & - & $\begin{array}{l}M=2.57 \\
S D=1.81\end{array}$ & $\begin{array}{l}M=2.43 \\
S D=1.78\end{array}$ \\
\hline
\end{tabular}


$87.2 \%$ of the students that took online exams only or a mix of online and in-person exams indicated that their institutions had not applied such assessment procedures in prior semesters.

Detailed frequencies of academic dishonesty in our sample can be found in Table 2. It is noteworthy that three out of five of the most frequently reported behaviors $(M>2.00)$ were directly tied to digital learning and online exams (i.e., absenteeism in online classes while being logged in, exchange with others during online tests, use of unallowed materials during online tests). While the mean scores indicate low frequencies in academic dishonesty, we also found that students showed a

Table 2

Prevalence of academic dishonesty-Sorted by relative frequency.

\begin{tabular}{|c|c|c|c|}
\hline Behavior & $M$ & $S D$ & $\%$ \\
\hline \multicolumn{4}{|l|}{ Academic Dishonesty } \\
\hline $\begin{array}{l}\text { Logging into an online course and engaging in other } \\
\text { activities during course time. }\end{array}$ & 4.45 & 2.04 & 88.1 \\
\hline $\begin{array}{l}\text { Solving tasks together with other students that were meant } \\
\text { as individual assignments. }\end{array}$ & 2.87 & 1.91 & 63.7 \\
\hline Referencing sources in term papers that one has not read. & 1.68 & 1.31 & 29.8 \\
\hline $\begin{array}{l}\text { Copying content from the internet, a book, or an article } \\
\text { without naming the source. }\end{array}$ & 1.50 & 1.01 & 26.4 \\
\hline $\begin{array}{l}\text { Deliberately listing sources in the bibliography that were } \\
\text { not used in writing the text. }\end{array}$ & 1.44 & 1.10 & 20.2 \\
\hline $\begin{array}{l}\text { Copying entire passages from other sources when writing } \\
\text { term papers without indicating through proper references. }\end{array}$ & 1.37 & 0.94 & 19.5 \\
\hline $\begin{array}{l}\text { Having others do individual assignments and handing them } \\
\text { in as own work. }\end{array}$ & 1.41 & 1.05 & 19.4 \\
\hline Making up excuses for missing a deadline. & 1.32 & 0.99 & 13.5 \\
\hline $\begin{array}{l}\text { Modifying information from scientific sources so that they } \\
\text { better fit one's line of argumentation. }\end{array}$ & 1.23 & 0.71 & 12.7 \\
\hline $\begin{array}{l}\text { Letting someone else sign a course attendance sheet to cover } \\
\text { up not being present in the course. }\end{array}$ & 1.29 & 0.95 & 11.3 \\
\hline $\begin{array}{l}\text { Convincing someone else to log into an online course under } \\
\text { a false alias to mimic participation. }\end{array}$ & 1.19 & 0.83 & 6.7 \\
\hline $\begin{array}{l}\text { Submitting the same work as a learning assignment for } \\
\text { different courses. }\end{array}$ & 1.13 & 0.63 & 6.0 \\
\hline $\begin{array}{l}\text { Handing in or presenting an entire piece of work of another } \\
\text { person as own work. }\end{array}$ & 1.08 & 0.48 & 4.0 \\
\hline $\begin{array}{l}\text { Deliberately trying to manipulate an instructor through } \\
\text { display of emotions (e.g., crying) to get deadline } \\
\text { extensions or better grades. }\end{array}$ & 1.07 & 0.45 & 3.5 \\
\hline $\begin{array}{l}\text { Changing a response after a performance assessment was } \\
\text { graded, then reporting that the assessment had been } \\
\text { misgraded and requesting credit for the altered response. }\end{array}$ & 1.06 & 0.47 & 2.3 \\
\hline $\begin{array}{l}\text { Trying to bribe an instructor to get deadline extensions or } \\
\text { better grades. }\end{array}$ & 1.05 & 0.39 & 2.1 \\
\hline Paying others to do one's own learning assignments. & 1.05 & 0.40 & 2.1 \\
\hline $\begin{array}{l}\text { Hiding or damaging books in the library to prevent others } \\
\text { from using them. }\end{array}$ & 1.03 & 0.31 & 1.4 \\
\hline $\begin{array}{l}\text { Deleting parts of online resources to prevent others from } \\
\text { using them. }\end{array}$ & 1.02 & 0.29 & 1.1 \\
\hline \multicolumn{4}{|c|}{ Cheating during on-site exams (only participants with at least one on-site exam) } \\
\hline $\begin{array}{l}\text { Using previous exams for preparation without permission to } \\
\text { do so. }\end{array}$ & 2.56 & 2.13 & 44.5 \\
\hline $\begin{array}{l}\text { Exchanging ideas with others about possible answers during } \\
\text { an examination.* }\end{array}$ & 1.55 & 1.20 & 23.7 \\
\hline Copying answers from someone else during an examination. & 1.38 & 0.96 & 18.7 \\
\hline $\begin{array}{l}\text { Solving exam questions by using additional materials or the } \\
\text { internet without permission.* }\end{array}$ & 1.45 & 1.13 & 18.4 \\
\hline Using cheat sheets during an examination. & 1.41 & 1.11 & 16.5 \\
\hline \multicolumn{4}{|c|}{ Cheating during online exams (only participants with at least one online exam) } \\
\hline $\begin{array}{l}\text { Solving exam questions by using additional materials or the } \\
\text { internet without permission.* }\end{array}$ & 2.51 & 1.98 & 48.6 \\
\hline $\begin{array}{l}\text { Exchanging ideas with others about possible answers during } \\
\text { an examination. * }\end{array}$ & 2.50 & 2.02 & 45.9 \\
\hline $\begin{array}{l}\text { Faking technical difficulties during examinations to gain an } \\
\text { advantage (e.g., more time, repetition of the exam). }\end{array}$ & 1.12 & 0.63 & 4.5 \\
\hline
\end{tabular}

Notes. Scales ranged from 1 (never) to 7 (very frequently). Time of reference was the summer semester of 2020. The fourth column (\%) indicates the relative frequency of students who indicated that they had engaged in the behavior by answering the item with a value $>1$. * Items were used to compare cheating during in-person and online tests. substantial number of different dishonest behaviors. Overall, only $4.9 \%$ of the participants reported that they had not engaged in any of the investigated behaviors during the summer semester 2020 at all, whereas $12.4 \%$ indicated that they had engaged in only one of the behaviors. In contrast, the vast majority of participants $(82.7 \%)$ indicated that they had engaged in multiple behaviors during the time in question $(M=4.79$ behaviors, $S D$ $=3.81$ behaviors). As particularly some of the more common behaviors might be considered as minor infractions or less severe (e.g., engaging in other activities during course time), we discarded the five most frequent behaviors with $M_{\text {frequency }}>2.00$ in an exploratory fashion. Still, only $28.6 \%$ of the students indicated that they had not engaged in any of the remaining, more severe, behaviors during the past semester and another $18.2 \%$ indicated that they had engaged in only one of the behaviors. In contrast, the majority of the participants (53.2\%) indicated that they had engaged in multiple remaining behaviors during the time in question ( $M$ $=2.60$ behaviors, $S D=3.09$ behaviors).

\subsection{Impact of examination mode on academic dishonesty}

We found very small effects of the mode of examination on the frequency measure of academic dishonesty, $F(2,1605)=4.46, p=.012, \eta^{2}$ $=0.006$. Paired post-hoc tests revealed that this main effect of examination mode was qualified through significant mean differences between pure online testing $(M=1.51, S D=0.49)$ and on-site testing $(M$ $=1.43, S D=0.42), t(1257)=-3.00, p=.003, d=-0.18$. In contrast, the rate of dishonesty for mixed testing $(M=1.47 ; S D=0.49)$ neither differed significantly from online testing, $t(732)=1.17, p=.243$ nor from on-site testing, $t(1221)=-1.41, p=.158$. However, neither the overall effect, $F(2,1605)=1.82, p=.162$, nor a post-hoc test for online versus on-site testing, $t(1257)=-1.76, p=.078$, reached significance when using the amount measure for academic dishonesty.

\subsection{Impact of mode of examination on cheating in exams}

The descriptive data shows trends for the postulated difference between modes of examination. More specifically, $31.7 \%$ of all students who had written on-site exams indicated that they had used unallowed assistance and/or engaged in direct exchange with other students during the assessment. For online testing, the number of persons engaging in these behaviors was almost twice as high with $61.4 \%$ reporting that they had engaged in either behavior.

These descriptive trends were qualified through mixed-model analyses showing that participants more frequently reported cheating in online tests $\left(M_{\text {frequency }}=2.22, S D=1.71\right)$ than in offline tests $\left(M_{\text {frequency }}\right.$ $=1.50, S D=0.99$ ) $, F(1,1193)=62.72, p<.001$ (see also Fig. 1). Using an approximation of Cohen's $d$ as suggested by Westfall et al. [55], we calculated an overall effect size of $d=0.55$ for the effect of mode of examination on cheating frequency. These effects were robust when using the amount measure for cheating in exams, $F(1,1162.7)=68.78, p$ $<.001, d=0.39$. The effect still remained stable when including the institution's experience with online exams as a potential moderator. We neither found a significant main effect of institution's experience with online exams, $F(1,1643.8)=0.09, p=.766$, nor a significant interaction effect, $F(1,1193)=0.51, p=.476$. The same was true when using the amount measure.

Finally, a repeated-measure ANOVA also showed that students that had been tested using both modes of examination reported a higher frequency of cheating in online exams $\left(M_{\text {frequency }}=2.43, S D=1.79\right)$ compared to on-site exams $\left(M_{\text {frequency }}=1.66, S D=1.08\right), F(1327)=$ 92.54, $p<.001, \eta^{2}=0.22$ (see also Fig. 1). The effect remained stable when using the amount measure for cheating in exams, $F(1327)=30.89$, $p<.001, \eta^{2}=0.09$. Controlling for the ratio between online and on-site exams did not change the pattern of the results substantially, $F(1326)=$ $94.64, p<.001, \eta^{2}=0.23$ (for the frequency measure); $F(1326)=27.61$, $p<.001, \eta^{2}=0.08$ (for the amount measure). 


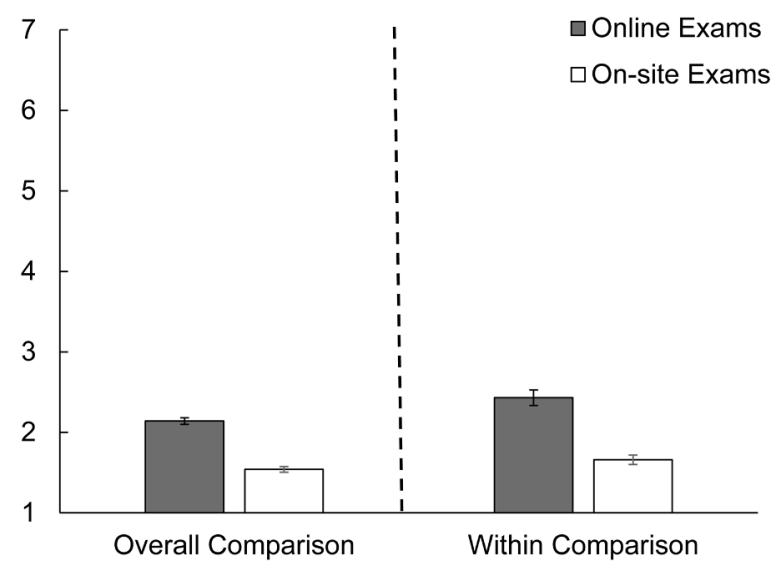

Fig. 1. Frequency of cheating in exams depending on examination mode Note. Scale ranged from 1 (never) to 7 (very frequently). Left side of the figure indicates the overall effect derived from mixed model analysis (full sample), while the right side indicates the effect derived from a repeated measure ANCOVA for those students who had taken both online and on-site exams (mixed testing group; $n=349$ students).

\section{Discussion}

Overall, our findings indicate that the sudden shifts from on-site to online testing in German higher education institutions during the COVID-19 pandemic in summer 2020 may have posed at least some threat to academic integrity. Students reported elevated rates of cheating in online exams compared to on-site exams. Furthermore, students whose performance was tested through both modes of examination reported cheating more frequently during online exams - albeit having taken a lower number of online then on-site exams (with the average difference being around one exam). Importantly, this finding contradicts the alternative explanation that our results might be merely due to differences between institutional cultures or students having more opportunities to cheat in online exams due to a higher number of online exams. In fact, as students took more on-site exams and thus had objectively more opportunities to cheat on-site, our results can be deemed as a rather conservative test. However, beyond these differences in cheating frequency during testing, a shift in the mode of examination to online testing during the pandemic did not seem to drastically increase the number of dishonest behaviors students engaged in, although it slightly increased the frequency of academic dishonesty. With that being said, we found that a high rate of the participating students reported to have engaged in behavior that can be labeled as academic dishonesty. More specifically, between $71.4 \%$ to $93.8 \%$ of the participating students (depending on whether we included the most frequent behaviors) reported that they had engaged in behaviors that infringe rules of academic integrity during this single critical semester. At this point, we cannot say whether these high rates are due to the specifics of our sample, typical for Germany (comparative data are lacking), or reflect a more general threat to academic integrity in the wake of the pandemic. It is noteworthy though, that most of the prevalent critical behaviors were directly bound to online teaching or online exams.

\subsection{Theoretical implications}

Our findings provide further cumulative evidence for the debate on whether online exams pose a risk for academic integrity. More specifically, we found that the implementation of online exams that likely had to be prepared in a short timeframe during summer 2020 was associated with increased cheating behavior in German higher education institutions (compared to on-site exams). First and foremost, this is a strong warning sign that (an ad-hoc shift to) online testing can make it difficult to uphold principles of academic integrity. Nevertheless, we found that the threat to academic integrity was mostly bound to the testing situation, while effects on other forms of academic dishonesty during the semester were small. This, in turn, speaks against the premise that ad-hoc online testing fosters a climate of dishonesty. Our study, thus, underlines the notion that ad-hoc online testing mostly affects behavior in the testing situation, while effects on the overall climate and broader measures of dishonesty are likely more negligible (in line with [26]). This also means that it is important to rely on measures tailored to assess behavior in the concrete situation rather than on omnibus measures of academic dishonesty when investigating the impact of modes of examination on academic integrity.

On a more practical note, we would like to highlight that the participants indicated that their institutions had little experience with online exams. While we did not find that the experience of an institution moderated the effect of the mode of examination on cheating, the number of participants from institutions with prior experience with online exams was rather small in all groups (accounting only for $12.8 \%$ of all students that were tested through online exams). It should be noted, though, that students might not be aware of all examination modes that are practiced at their university, thus, assessing institutional experience with a more objective measure might be commendable in future studies. However, even institutions or instructors that had already used online exams in the past were likely unprepared for the challenges evolving in the wake of a global pandemic. The simultaneously emerging needs to adapt teaching, communication, and examination were a strong challenge for instructors and administration alike that was often experienced as straining and distressful [4]. In such a climate, maintaining academic integrity likely often became a secondary priority compared to maintaining a minimum of instruction and managing limited resources.

At the same time, students were likely highly stressed as well. Among other stressors, also due to being exposed to a multitude of novel online teaching and examination methods and unclear communication from educators and universities. This may have decreased expectations to succeed in exams, which could explain further why students considered cheating as viable behavior under conditions of low accountability (i.e., during online exams). Related to this, we would like to emphasize that we do not mean to imply that "helpless" educators were victims of "opportunistic" students during the COVID-19 pandemic. Instead, the elevated rates of cheating were probably the result of a multitude of factors that increased stress on both sides due to the demands of a highly unpredictable situation, in combination with impaired accountability in swiftly implemented ad-hoc online examinations.

\subsection{Potential avenues to reduce cheating rates in online exams}

While our research provides important empirical insights into the prevalence of cheating in ad-hoc online exams, it is not suitable to provide evidence on the impact of different practical solutions for the presented problem. However, existing research may inspire at least three promising avenues to address the issue: Increasing accountability through proctoring, applying examination modes that reward deep understanding, and shifting teaching from a focus on performance to a stronger focus on learning.

First, increasing accountability is a method to counteract perceptions that cheating online has a high likelihood of remaining undetected. Particularly, proctoring online exams could mitigate the effects that we found in our sample $[2,3,27]$. However, at this point, most higher education institutions (in general and likely also in our sample) still lack experience, equipment, or clear guidelines to use proctoring in online exams [13]. Closing this gap in testing methodology could thus be an important step forward for higher education institutions around the world as online exams are increasingly used for performance assessment, particularly as the pandemic continues.

Second, it is important to clarify that the perceived feasibility of cheating not only depends on accountability, but also on the complexity 
of the exam. Recent laboratory research has shown that the way performance is evaluated in a performance test can impact cheating rates. More specifically, students were less likely to cheat in a performance test if they assumed that the instructor would later grade the process of solving the question rather than just the correct results. This was the case even though good performance was incentivized through monetary rewards and the responsible examiner left the room for a prolonged time during the experiment [6]. The observed reduction of cheating is likely rooted in correctly copying a consistent work process being more difficult than just copying the answers from other sources (such as fellow students' answers). For practitioners, this could mean that to decrease cheating, it might be beneficial to rely on exams that are more strongly characterized by open questions that require the students to truly reflect about the subject matter and show through their writing that they have gained a deep understanding of the learning contents. In contrast, closed questions, multiple choice items, and simple reproduction of knowledge may make it easier to evaluate whether a question is answered right or wrong, but could also be more susceptible to fraud.

Third, a substantial body of research has shown that students who have developed strong learning goals (defined as the striving for competence development) are less likely to cheat in exams (subsumed in a recent meta-analysis, [31]). This is probably because students with a strong learning focus consider cheating as a costly shortcut that undermines true understanding. Fostering learning goals in students makes it necessary to provide instruction that takes students' interests and needs into account. Particularly, research has shown that giving students autonomy over their learning process, providing valuable feedback and recognition as well as a collaborative learning climate can evoke learning goals in students [36]. It should be noted that enacting such learning structures might be challenging but that it might also be an effective way to yield lower cheating rates regardless of the mode of examination.

Finally, while we note an increase in infringement against academic rules, those rules themselves can be subject to debate. For instance, universities and instructors could allow students to use older exams for preparation, as this material may foster a deeper understanding of the learning subject. In the same vein, one might argue that the ability to memorize information is less valuable than knowing how to research and integrate information. As such, open-book online exams may allow to lift the ban on using helpful material during examination, which could foster deep processing of the learning content over surface learning [57]. Similar arguments could be made for collaborative exams that allow students to foster their abilities to cooperate with others and to explore the learning content together [48]. While both open-book exams and collaborative exams may be less feasible on-site due to constrictions of the examination situation (necessary space, availability of technology, level of noise due to cooperation), the feasibility of such examination procedures could become a true asset of wide(r) spread online examination procedures. In sum, we argue that uncovering deviations from academic norms does not necessarily mean that universities have to further restrict examination situations to uphold these norms but could also spark debate about the meaningfulness regarding some of these norms.

\subsection{Limitations and suggestions for future research}

Our data strongly reflect an unprecedented situation shaping a special learning environment that challenged instructors [4] and students $[24,35]$ alike. This is both a strength and a limitation of our observations and findings. While our study can contribute to understanding some of the challenges that the rapid digitalization in the wake of COVID-19 imposed on educational institutions, the results also reflect this special situation. For instance, it was striking that such a high rate of students admitted having engaged in some sort of critical behavior during a single semester. This might partly reflect that students struggled with the demands of a new virtual learning environment such as the need for digital literacy and the ability to structure and organize one's learning process in a more self-regulated way than before the pandemic [24]. As a result, even students who normally might not have engaged in academic dishonesty, may have been more inclined to do so under the special circumstances. This may have been especially true when online exams were used as an examination method due to (anticipated) reduced accountability.

Additionally, it is possible that instructors were ambiguous in their communication of academic standards regarding cheating in online environments, as the distressing situation during the pandemic may have impeded the development of a clear communication strategy. Ambiguous communication and standards that varied between instructors, however, might have enhanced students' inclination to cheat in online environments as students typically rely on the information given by faculty to evaluate whether their behavior is justifiable [29, 45]. In sum, the special situation during the onset of the pandemic could have fostered insecurities in students as wells as instructors, which could have led to elevated cheating rates in online environments. Whether a sudden shift to online testing under normal conditions (in-person teaching, no existential threat bound to a deadly global pandemic) evokes such a spike in cheating behavior as observed in this study must be further tested in future studies.

As we relied on self-reports and due to academic dishonesty being considered socially undesirable, we assume that the behavior reported by the students represents an underestimation of the actual magnitude of academic dishonesty [10]. Besides social desirability, one may argue that students acting dishonestly in exams may also be more likely to lie in online surveys. However, dishonest behavior is typically directed towards potential gains that are bound to the respective context. This is why situational factors strongly influence dishonest behavior (see [39]; also [43]). While (successful) dishonest behavior has direct positive consequences in the context of examination (i.e., good grades), this does not apply to an anonymous online survey in which dishonesty does not result in substantial benefits. The high reported rates of dishonest behavior that we observed in our study further underline this notion, as we have little reason to believe that students at large were inclined to exaggerate their engagement in socially unaccepted behaviors.

However, discussing alternate measures for academic cheating may be helpful to get a better understanding on the value and limitations of using self-reports for research into dishonest behavior. In this regard, some researchers have relied on more indirect measures (e.g., concerns of instructors, [42]; increase in performance compared to prior cohorts, [11]). While undoubtedly insightful, these alternative assessments of cheating have in common that they rely on additional inferences, for instance that elevated concerns by educators are indeed valid or that better performance must be at least partly rooted in dishonest behavior. There is a plethora of factors like the credibility of instructors' judgments about cheating or changes in the difficulty of exams during the pandemic that complicate such inferences. If individuals admit to cheating in an exam via self-reports, however, additional inferences are not needed. Furthermore, even though social desirability bias may impact the observed cheating rates, it is unlikely that this bias would impact reports of cheating in on-site versus online exams differently. Importantly, we assessed whether students had engaged in actual behavior (retrospective admission of critical behavior) rather than measuring their personal willingness to do so (prospective inference of future behavior) because it is yet unclear how the latter translates into behavior (see [25,49] for diverging positions).

An alternative assessment of cheating would be observations of actual cheating behavior in the situation. This, however, comes with the caveat of additional ethical and practical considerations regarding the feasibility to directly observe cheating without informing student services and without having the observation interfere with students' behavior (and thus breaching anonymity as well as increasing accountability). This often limits observation of cheating to laboratory research which allows for deception of participants under avoidance of 
ethical pitfalls (i.e., [5]). Laboratory research, in turn, is limited regarding external validity, as the experimental tasks that participants work on hardly have the same relevance as their actual exams. Taken together, this underscores a) the value of data from student self-reports, which should b) always be interpreted in a larger research framework that makes use of a multitude of designs to compensate for the limitations of this measure.

Even though our sample is not representative, it is unlikely that our sampling strategy resulted in a sample of students who are more prone to dishonesty than their peers. Particularly, we did not disclose that we were specifically interested in dishonesty when advertising the study and used a systematic recruitment procedure through official mailing lists. Additionally, empirical research has shown that voluntary survey studies are more likely to lead to underestimations of cheating rates [41]. Against this background, we consider the rather high rates of academic dishonesty in our sample to be concerning, as a majority of the participating students reported that they had infringed rules of academic integrity over the course of only one semester. While this may not be a direct effect of a shift to online testing (non-significant effect on number of behaviors), the elevated rates could reflect a shift in culture due to more absent and overwhelmed instructors and unclear rules in the hastily assembled online learning environments. Unfortunately, we cannot test this assumption as we lack a comparison group indicating academic dishonesty during a regular semester. Future studies might thus consider comparing COVID-19 data on academic dishonesty (as presented in this study) with rates of academic dishonesty in the upcoming years. Furthermore, we think it is important to qualify our findings across different countries that chose to enact large-scale digitalization in their higher education sector to infer whether our results can be generalized.

Another issue with the frequentist approach to measuring dishonest behavior was that the judgment of the relative frequency of the different behaviors was made by the students themselves, which makes it more prone to subjective interpretation. However, the same cannot be said for the analyses with the amount measures, as the judgement of whether one engaged in a certain behavior or not is likely far less biased. The general magnitude of the effect sizes and the fact that we found the association between mode of examination and cheating both on the frequency measure, the amount measure, and also for students whose performance was examined through both online and on-site exams, enhances our confidence in the robustness of our findings.

Finally, it is important to note that the conducted research put a strong focus on the impact of examination mode on academic dishonesty. Researchers have postulated a multitude of additional factors bound to the individual (e.g., achievement motivation, [43] or personality, [25]) and to the situation (e.g., social norms, [40]) that impact dishonest behavior (see [18] for an overview). These factors may at least partly explain the observed associations between examination mode and cheating (as we discussed for instance regarding students' expectations of reduced costs for cheating in online examination; in line with [16, 29]). It is an important avenue for future research to investigate whether additional personal and situational factors discussed in the literature mediate or moderate the impact of examination mode on academic cheating.

\section{Conclusions}

The worldwide COVID-19 pandemic has posed severe challenges for societies across the globe. One of these emerging challenges was the need for rapid digitalization of all life domains including education. Our study shows that the imposed pressure on the education system also put a strain on academic integrity. We found high rates of self-admitted academic dishonesty reported by students for the summer semester of 2020. Moreover, the rate of cheating in exams during this time depended on the examination mode, with online exams being more prone to the use of unpermitted assistance then on-site exams. An upside to these findings is that they challenge higher education institutions to find answers on challenges that were already emerging and merely accelerated by the pandemic. Online testing will likely be a phenomenon of remaining and increasing relevance. This development carries both dangers and opportunities for performance assessment in higher education. The broad implementation and rigorous testing of procedures that mitigate cheating through higher accountability or complexity as well as the discussion of academic norms that may hinder the implementation of new and innovative modes of examination (e.g., open-book and collaborative exams) is therefore an important task for educational research and practice.

\section{Declaration of Competing Interest}

The authors declare that they have no known competing financial interests or personal relationships that could have appeared to influence the work reported in this paper.

\section{Acknowledgments}

The presented research was made possible through a research grant by the German Research Foundation to Stefan Janke (JA 3137/1-1) and Martin Daumiller (DA 2392/1-1). We thank Elisabeth Limberg, Danielle Schrepfer as well as Paula Schmelzer for their assistance with programming and data collection and Caroline Tremble for her valuable services in language editing.

\section{References}

[1] Akbulut Y, Şendağ S, Birinci G, Kılıçer K, Şahin MC, Odabaşı HF. Exploring the types and reasons of Internet-triggered academic dishonesty among Turkish undergraduate students: development of Internet-Triggered Academic Dishonesty Scale (ITADS). Comput Educ 2008;51(1):463-73. https://doi.org/10.1016/j. compedu.2007.06.003.

[2] Alessio HM, Malay N, Maurer K, Bailer AJ, Rubin B. Examining the effect of proctoring on online test scores. Online Learn 2017;21(1):146-61.

[3] Arnold IJ. Cheating at online formative tests: does it pay off? Internet High Educ 2016;29:98-106. https://doi.org/10.1016/j.iheduc.2016.02.001.

[4] Daumiller M, Rinas R, Hein J, Janke S, Dickhäuser O, Dresel M. Shifting from faceto-face to online teaching during COVID-19: The role of university faculty achievement goals for attitudes towards this sudden change, and their relevance for burnout/engagement and student evaluations of teaching quality. Computers in Human Behavior 2021;118:106677. https://doi.org/10.1016/j.chb.2020.106677.

[5] Daumiller M, Janke S. Effects of performance goals and social norms on academic dishonesty in a test. British Journal of Educational Psychology 2020;90(2):537-59. https://doi.org/10.1111/bjep.12310.

[6] Daumiller M, Janke S. The impact of performance goals on cheating depends on how performance is evaluated. AERA Open 2019;5(4):2332858419894276. https://doi.org/10.1177/2332858419894276.

[7] Bashir H, Bala R. Development and validation of academic dishonesty scale (ADS): presenting a multidimensional scale. Int J Instr 2018;11(2):57-74. https://doi.org/ 10.12973/iji.2018.1125a.

[8] Bates D, Maechler M, Bolker B, Walker S. Fitting linear mixed-effects models using lme4. J Stat Softw 2015;67(1):1-48. https://doi.org/10.18637/jss.v067.i01.

[9] Bernardi RA, Metzger RL, Bruno RGS, Hoogkamp MAW, Reyes LE, Barnaby GH. Examining the decision process of students' cheating behavior: an empirical study. J Bus Eth 2004;50(4):397-414. https://doi.org/10.1023/B: BUSI.0000025039.47788.c2.

[10] Bernardi RA, Adamaitis KL. Data contamination by social desirability response bias: an international study of students' cheating behavior. Res Prof Responsib Eth Account 2007;11:157-84. https://doi.org/10.1016/S1574-0765(06)11008-0.

[11] Bilen E, Matros A. Online cheating amid COVID-19. J Econ Behav Org 2020;182: 196-211. https://doi.org/10.1016/j.jebo.2020.12.004.

[12] Burrus RT, McGoldrick K, Schuhmann PW. Self-reports of student cheating: does a definition of cheating matter? J Econ Educ 2007;38(1):3-16. https://doi.org/ 10.3200/JECE.38.1.3-17.

[13] Butler-Henderson K, Crawford J. A systematic review of online examinations: a pedagogical innovation for scalable authentication and integrity. Comput Educ 2020. https://doi.org/10.1016/j.compedu.2020.104024. Advance online publication.

[14] Chirikov I, Shmeleva E, Loyalka P. The role of faculty in reducing academic dishonesty among engineering students. Stud High Educ 2020;45(12):2464-80. https://doi.org/10.1080/03075079.2019.1616169.

[15] Clark TM, Callam CS, Paul NM, Stoltzfus MW, Turner D. Testing in the time of COVID-19: a sudden transition to unproctored online exams. J Chem Educ 2020;97 (9):3413-7. https://doi.org/10.1021/acs.jchemed.0c00546. 
[16] Costley J. Student perceptions of academic dishonesty at a cyber-university in South Korea. J Acadc Eth 2019;17(2):205-17. https://doi.org/10.1007/s10805018-9318-1.

[17] Crawford J, Butler-Henderson K, Rudolph J, Malkawi B, Glowatz M, Burton R, Magni P, Lam S. COVID-19: 20 countries' higher education intra-period digital pedagogy responses. J Appl Learn Teach 2020;3(1):1-20. https://doi.org/ 10.37074/jalt.2020.3.1.7.

[18] Crown DF, Spiller SM. Learning from the literature on collegiate cheating: a review of empirical research. J Bus Eth 1998;17:683-700. https://doi.org/10.1023/A: 1017903001888.

[19] Daffin LW, Jones AA. Comparing student performance on proctored and nonproctored exams in online psychology courses. Online Learn 2018;22(1): 131-45. https://doi.org/10.24059/olj.v22i1.1079.

[20] Daniels LM, Goegan LD, Parker PC. The impact of COVID-19 triggered changes to instruction and assessment on university students' self-reported motivation, engagement and perceptions. Soc Psychol Educ 2021;24:299-318. https://doi.org/ 10.1007/s11218-021-09612-3.

[21] Davis SF, Grover CA, Becker AH, McGregor LN. Academic dishonesty: prevalence, determinants, techniques, and punishments. Teach Psychol 1992;19(1):16-20. https://doi.org/10.1207/s15328023top1901_3.

[22] Gamage KA, Silva EKd, Gunawardhana N. Online delivery and assessment during COVID-19: safeguarding academic integrity. Educ Sci 2020;10(11):301. https:// doi.org/10.3390/educsci10110301.

[23] Grijalva TC, Kerkvliet J, Nowell C. Academic honesty and online courses. Coll Stud J 2006;40(1):180-5.

[24] Hamdan KM, Al-Bashaireh AM, Zahran Z, Al-Daghestani A, Samira AH, Shaheen AM. University students' interaction, Internet self-efficacy, self-regulation and satisfaction with online education during pandemic crises of COVID-19 (SARSCoV-2). Int J Educ Manag 2021. https://doi.org/10.1108/IJEM-11-2020-0513/ full/html.

[25] Heck DW, Thielmann I, Moshagen M, Hilbig BE. Who lies? A large-scale reanalysis linking basic personality traits to unethical decision making. Judgm Decis Mak 2018;13(4):356-71.

[26] Holden, O., Kuhlmeier, V.A., \& Norris, M. (2020). Academic integrity in online testing: a research review. PsyArXiv. 10.31234/osf.io/rjk7g.

[27] Hylton K, Levy Y, Dringus LP. Utilizing webcam-based proctoring to deter misconduct in online exams. Comput Educ 2016;92:53-63. https://doi.org/ 10.1016/j.compedu.2015.10.002.

[28] Khan ZR, Balasubramanian S. Students go click, flick and cheat... e-cheating, technologies and more. J Acad Bus Ethics 2012;6:1-26.

[29] King CG, Guyette RW, Piotrowski C. Online exams and cheating: an empirical analysis of business students' views. J Educ Online 2009;6(1):1-11.

[30] King DL, Case CJ. E-cheating: incidence and trends among college students. Issues Inf Systems 2014;15(1):20-7. https://doi.org/10.48009/1 iis_2014_20-27.

[31] Krou MR, Fong CJ, Hoff MA. Achievement motivation and academic dishonesty: a meta-analytic investigation. Educ Psychol Rev 2020;33:427-58. https://doi.org/ 10.1007/s10648-020-09557-7.

[32] Kuznetsova A, Brockhoff PB, Christensen RHB. lmerTest Package: tests in linear mixed effects models. J Stat Softw 2017;82(13):1-26. https://doi.org/10.18637/ jss.v082.i13.

[33] Ladyshewsky RK. Post-graduate student performance in 'supervised in-class' vs.'unsupervised online'multiple choice tests: implications for cheating and test security. Assess Eval High Educ 2015;40(7):883-97. https://doi.org/10.1080/ 02602938.2014.956683.

[34] Lanier MM. Academic integrity and distance learning. J Crim Justice Educ 2006;17 (2):244-61. https://doi.org/10.1080/10511250600866166.

[35] Lestari, W., Aisah, L., \& Nurafifah, L. (2020). What is the relationship between selfregulated learning and students' mathematical understanding in online lectures during the covid-19 pandemic? Paper presented at the 2nd International Seminar on Applied Mathematics and Mathematics Education (2nd ISAMME), Cimahi, Indonesia.
[36] Lüftenegger M, Van De Schoot R, Schober B, Finsterwald M, Spiel C. Promotion of students' mastery goal orientations: does TARGET work? Educ Psychol (Lond) 2014;34(4):451-69. https://doi.org/10.1080/01443410.2013.814189.

[37] Marinoni G, Van't Land H, Jensen T. The impact of covid-19 on higher education around the world. International Association of Universities; 2020.

[38] McCabe DL. It takes a village: academic dishonesty \& educational opportunity. Lib Educ 2005;91(3):26-31.

[39] McCabe DL, Trevino LK. Individual and contextual influences on academic dishonesty: a multicampus investigation. Res High Educ 1997;38(3):379-96. https://doi.org/10.1023/A:1024954224675.

[40] McCabe DL, Trevino LK, Butterfield KD. Dishonesty in academic environments: the influence of peer reporting requirements. J High Educ 2001;72(1):29-45. https:// doi.org/10.1080/00221546.2001.11778863.

[41] Miller A, Shoptaugh C, Parkerson A. Under reporting of cheating in research using volunteer college students. Coll Stud J 2008;42(2):326-39.

[42] Moralista R, Oducado RM. Faculty perception toward online education in higher education during the coronavirus disease 19 (COVID-19) pandemic. Univ J Educ Res 2020;8(10):4736-42. https://doi.org/10.13189/ujer.2020.081044.

[43] Murdock TB, Anderman EM. Motivational perspectives on student cheating: toward an integrated model of academic dishonesty. Educ Psychol 2006;41(3): 129-45. https://doi.org/10.1207/s15326985ep4103_1.

[44] Nguyen JG, Keuseman KJ, Humston JJ. Minimize online cheating for online assessments during COVID-19 pandemic. J Chem Educ 2020;97(9):3429-35. https://doi.org/10.1021/acs.jchemed.0c00790.

[45] Raines DA, Ricci P, Brown SL, Eggenberger T, Hindle T, Schiff M. Cheating in online courses: the student definition. J Effect Teach 2011;11(1):80-9.

[46] Richardson R, North M. Strengthening the trust in online courses: a common sense approach. J Comput Sci Coll 2013;28(5):266-72.

[47] Rogers CF. Faculty perceptions about e-cheating during online testing. J Comput Sci Coll 2006;22(2):206-12. https://doi.org/10.5555/1181901.1181936.

[48] Shen J, Hiltz SR, Bieber M. Learning strategies in online collaborative examinations. IEEE Trans Prof Commun 2008;51(1):63-78. https://doi.org/ 10.1109/TPC.2007.2000053.

[49] Steger D, Schroeders U, Wilhelm O. Caught in the act: predicting cheating in unproctored knowledge assessment. Assessment 2021;28(3):1004-17. https://doi. org /10.1177/1073191120914970.

[50] Stiles BL, Wong NCW, LaBeff EE. College cheating thirty years later: the role of academic entitlement. Deviant Behav 2018;39(7):823-34. https://doi.org/ 10.1080/01639625.2017.1335520.

[51] Stuber-McEwen D, Wiseley P, Hoggatt S. Point, click, and cheat: frequency and type of academic dishonesty in the virtual classroom. Online J Distance Learn Adm 2009;12(3). Retrieved from, http://www.westga.edu/ distance/ojdla/fall123/st uber123.html.

[52] Teixeira AA, Rocha MF. Cheating by economics and business undergraduate students: an exploratory international assessment. High Educ 2010;59(6):663-701. https://doi.org/10.1007/s10734-009-9274-1.

[53] Varble D. Reducing cheating opportunities in online test. Atl Market J 2014;3(3): 131-49.

[54] Watson G, Sottile J. Cheating in the Digital Age: do students cheat more in on-line courses? Online J Distance Learn Adm 2008;13(1). Retrieved from, https://mds. marshall.edu/cgi/viewcontent.cgi? article $=1000 \&$ context=eft faculty.

[55] Westfall J, Kenny DA, Judd CM. Statistical power and optimal design in experiments in which samples of participants respond to samples of stimuli. J Exp Psychol Gen 2014;143(5):2020-45. https://doi.org/10.1037/xge0000014.

[56] Wigfield A, Eccles JS. Expectancy-value theory of achievement motivation. Contemp Educ Psychol 2000;25(1):68-81. https://doi.org/10.1006/ ceps.1999.1015.

[57] Williams JB, Wong A. The efficacy of final examinations: a comparative study of closed-book, invigilated exams and open-book, open-web exams. Br J Educ Technol 2009;40(2):227-36. https://doi.org/10.1111/j.1467-8535.2008.00929.x. 